\title{
Bal Arısı (Apis Mellifera L., 1758) Kolonilerinde Hijyenik Davranışa Etki Eden Faktörler ile Tespit Yöntemlerinin Karşılaştırması Üzerine Bir Çalışma
}

\author{
Ethem Akyol*
}

Ömer Halisdemir Üniversitesi, Tarım Bilimleri ve Teknolojileri Fakültesi, Hayvansal Üretim ve Teknolojileri Bölümü, 51240 Niğde, Türkiye

\section{A K A L E B İ L G İ S İ}

Geliş 20 Ekim 2016

Kabul 18 Kasım 2016

Çevrimiçi bask1, ISSN: 2148-127X

Anahtar Kelimeler:

Hijyenik davranış

Sivi azot

İğneleme yöntemi

Koloni

Bal arıs1

$\overline{\text { *Sorumlu Yazar: }}$

\section{Ö Z E T}

Bu çalışma bal arısı hastalık ve zararlılarına karşı mücadelede, hijyenik davranış özelliği yüksek olan kolonileri belirlemede kullanılacak hijyenik davranış yöntemini belirlemek amacıyla yürütülmüştür. Çalışmada deneme materyali olarak 40 koloni kullanılmıştır. İlk yıl koloniler 20'şerli iki gruba ayrılmış ve bu gruplardan birincisi sıvı azot, ikincisine iğneleme (pin-killing) yöntemi ile hijyenik davranış testi uygulanarak hangi yöntemin daha başarılı olduğu belirlenmeye çalışılmıştır. Sıvı azot uygulaması (I.Grup) ve iğneleme yapılan (II. Grup) kolonilerde \% (ortalama \pm S.H) temizleme oranları $66,25 \pm 14,98$ ve $78,10 \pm 12,10$ olarak belirlenmiştir. Birinci yıl hijyenik davranış oranı en yüksek olan koloni ikinci yıl damızlık olarak kullanılmış ve bu koloniden alınan larvalarla ana arı yetiştirilerek kızkardeş ana arılardan oluşturulan 5 araştırma grubunda her biri 8 koloniden oluşan toplam 40 kolonili deneme arılı̆̆ düzenlenmiştir. Gruplar farklı hacim ve ergin arı yoğunluğuna göre düzenlenmiștirler. Araştırma grupları; standart kovanda 9 çerçeve arılı (I. Grup), standart kovanda 5 çerçeve arılı (II. Grup), 5 çerçeveli ruşet kovanda 5 çerçeve arılı (III. Grup), 5 çerçeveli ruşet kovanda 3 çerçeve arılı (IV. Grup) ve son olarak strafor çiftleştirme kutusu (V. Grup) oluşturulmuştur. Araştırma kolonilerine ikişer ay ara ile (Mayıs-Eylül) 3 defa iğneleme yöntemi (pin-killing) ile hijyenik test uygulaması yapılarak mevsim, kovan hacmi ve işçi an yoğunluğunun temizleme davranışı üzerine etkileri belirlenmeye çalışılmışıtır. İkinci yıl yapılan uygulamalarda 1., 2., 3., 4., ve 5. gruplarda (\% ortalama \pm S.H.) temizleme oranlar1 sirasiyla $70,54 \pm 9,34,58,38 \pm 8,44,70,63 \pm 7,75,54,96 \pm 6,8$ ve $58,21 \pm 6,91$ olarak belirlenmiştir. Koloniler iğneleme yönteminde sıvı azot ile dondurma yöntemine göre daha yüksek oranda bir temizleme davranışı gösterirken, birim alandaki arı yoğunluğunun en fazla olduğu 1. ve 3 . Grup kolonilerde temizleme oranı diğer gruplara göre daha yüksek olmuștur.

Turkish Journal Of Agriculture - Food Science And Technology, 4(12): 1207-1211, 2016

A Study on Method Development in Hygienic Behaviour in Honeybee Colonies (Apis Mellifera L., 1758)

\section{A R T I C LE I N F O}

Article history:

Received 20 October 2016

Accepted 18 November 2016

Available online, ISSN: 2148-127X

Keywords:

Hygienic behaviour

Liquid nitrogen

Pin-killing method

Colony

Honeybee

*Corresponding Author:

E-mail: eakyol@nigde.edu.tr

\section{A B S T R A C T}

This study was conducted to determine the better hygienic behaviour determination method that is used in controlling against bee diseases and pests. Total forty honeybee colonies (Apis mellifera anatoliaca) were used and they were randomly divided into two groups (each group consists of twenty colonies) in first year. Liquid nitrogen method was used in the first group' colonies and pin-killing (needling process) method was used in the second group' colonies to determine the effectiveness of methods for hygienic behaviour. Average clearance rate was found as $66.25 \%$ and $78.10 \%$ in the first (Liquid nitrogen application) and the second (pinkilling) groups respectively. In the second year, forty colonies were divided into five equal groups and each group consisted eight colonies. The first group consisted of 9 frames bees in standard langstroot hive (10 frame capacity), the second group consisted of 5 frames bees in standard langstroot hive ( 10 frame capacity), the third group consisted of 5 frames bees in ruşet hive ( 5 frame capacity), the forth group's consisted of 3 frames bees in ruşet hive ( 5 frame capacity) and the fifty group consisted of queen mating hive. The pin-killing (needling process) method, tested in first year, was used for all groups to determine the effectiveness of colony population and the size of hive. Average clearance rates of the first, second, third, forth and fifth groups were $70.54 \%, 58.38 \%, 70.63 \%, 54.96 \%$ and $58.21 \%$ respectively. The colonies that belonged to the pin-killing (needling) group showed a higher cleaning behaviour rate than the other colonies. The density of bees in hive had an important effect on the clearance rate of colonies. The colonies of group 1 and group 3, which had the more density of bees in per unit area, had the higher clearance rate than the other groups. 


\section{Giriş}

Türkiye uygun ekolojisi, zengin bitki örtüsü ve yaklaşık yedi milyon koloni varlığı ile büyük bir arıcılık potansiyeline sahiptir (Anonim, 2014). Kolonilerin verimliliğini etkileyen hastalık ve parazitler; Amerikan Yavru çürüklüğü, Avrupa Yavru çürüklüğü, nosema, kireç, septisemi, arı felci, varroa ve bal mumu güvesi şeklinde sıralanabilir (Akyol ve Korkmaz, 2006; Akyol ve ark., 2007). Bu parazit ve zararlılardan bazıları sadece kolonilerin verimliliğini etkileyerek zarar verirken bazıları özellikle ileri aşamalarında kolonilerin sönmesine neden olabilmektedirler (Tutkun ve İnci, 1992). Hastalık ve parazitlerin zararlarını azaltmak veya yok etmek amacıyla kullanılan kimyasalların bazıları arı ürünlerinde kalıntı bırakarak uzun y1llar birikmekte ve belli düzeye ulaştığında bu kalıntılar ile bulaşık ürünleri tüketimi arı ve insan sağlığına olumsuz etkiler yapmaktadır (Ginevan ve ark., 1982).

Tüm canlılar doğal yaşam alanlarında hastalık ve zararlılara karşı bazı tepkiler ve direnç mekanizmaları geliştirerek yaşamlarını kimyasalların yaygın olarak kullanılmaya başlandığı yüz yılımıza kadar sürdürmüşlerdir. $\mathrm{Bu}$ süreçte insanların bazı canlıların doğal yaşam alanlarını değiştirmesi, tahrip etmesi ve bu canlılardan ekonomik öneme sahip olanları kendi tüketim ihtiyaçlarına cevap vermeye zorlaması neticesinde zaman içerisinde birtakım yeni hastalık, zararlı ve diğer yaşamsal sorunlar ortaya çıkmaktadır. Bunlardan en önemlisi tüm dünyada son 40-50 yıldır önemli zararlara yol açan ve hala en büyük problemlerden biri olarak değerlendirilen ve bir dış parazit olan varroadır (Varroa destructor).

Bal arıları yüzyıllardır yeryüzünde değişen çevre koşullarına ve düşmanlarına karşı adapte olarak bazı savunma mekanizmaları geliştirmişlerdir. $\mathrm{Bu}$ mekanizmalardan en önemlisi bazı hastalık ve parazitlere karşı arıların gösterdikleri hijyenik davranıştır. Bu davranış ilk olarak 1937 yılında Dr. O.W. Park tarafından tanımlanmıștır. Burada birbirinden ayrı iki davranış mekanizması gözlenmektedir. Bunlardan biri hastalıklı, sırlanmış kuluçka gözlerinin açılması, diğeri ise hastalıklı larvaların bu gözlerden çıkarılarak kovan dişına atılmasıdır. Bu iki davranış mekanizması 1964 yılında Dr. Rothenbuhler tarafından gösterilmiştir. Laidlaw ve Page (1997) yılında yaptıkları çalışmada hijyenik davranışın, Amerikan yavru çürüklüğü, Avrupa yavru çürüklüğü, kireç hastalıklarına ve varroa parazitine karşı etkili bir davranış mekanizması olduğunu bildirmişlerdir. Tüm dünyada her geçen gün yaygınlaşan Amerikan yavru çürüklüğü (Paenibacillus larvae), Avrupa yavru çürüklüğü (Melisococcus pluton), kireç hastalığı (Ascosphaera apis) ve varroa (Varroa destructor) dünya arıcılığının en önemli sorunları haline gelmiştir. Bu hastalık ve parazitlerle mücadelede sürekli kimyasal mücadele tercih edilmiş ve bunun sonucu olarak kullanılan kimyasalların etkili maddelerine karşı hedef organizmalarda direnç gelişmiştir (Milani, 1995; Milani ve ark., 1995).

Morfolojik ve fizyolojik olarak oldukça farklı çok sayıda balarısı ırk ve ekotiplerini barındıran ülkemizde ırklar arasında ve aynı ırk içerisindeki koloniler arasında çeşitli özellikler bakımından oldukça geniş bir varyasyon bulunmaktadır (Genç ve ark., 1999; Akyol ve Kaftanoğlu
2001).

Bal arılarının geleceğini ve sağlıklı arı ürünleri üretiminin garanti altına alanabilmesi için arıların hastalık ve zararlılara karşı direnç mekanizmasının artırılması ve kimyasal kullanımının en az seviyeye çekilmesi arıcılık sektörünün başlıca hedeflerinden birisidir.

$\mathrm{Bu}$ çalışma bal arılarının hastalık ve parazitlere karşı ne derecede dirençli olduğu Hijyenik davranışlarını belirlemede kullanılan sıv1 azot ve toplu iğne yöntemlerinden hangisinin daha etkili olduğu ve hangi mevsimde, hangi güçteki kolonilerde yapılan testlerin hijyenik davranışı ölçmede daha etkili olduğunu belirlemek amacıyla Ulukışla Meslek Yüksekokulunda yürütülmüştür.

\section{Materyal ve Metot}

Çalışmada arı materyali olarak Ulukışla Meslek Yüksekokuluna ait kolonileri ile 20 adet özel arıcılık işletmelerinden temin edilen bal arısı kolonileri kullanılmıştır. Orta Anadolu Bölgesinde yetiştiriciliği yapılan kolonilere hijyenik davranış testleri yapılmıştır. Yüksek hijyenik davranış gösteren 20 adet balarısı (Apis mellifera L.) kolonisi araştırmada kullanılacak ana arıların ebeveynleri olarak seçilmiştir. Yetiştirilen ana arılar ile araştırma kolonilerinin ana arıları yenilenerek toplam 40 koloni deneme materyali olarak hazırlanmıştır.

Araştırma kolonileri ilk yıl 20'şerli iki gruba ayrılmış ve bu gruplardan birincisine sıvı azot, ikincisine iğneleme yöntemi ile hijyenik davranış testi uygulanarak hangi yöntemin daha başarılı olduğu belirlenmiştir.

İkinci y1l her biri 8 koloniden oluşan 5 araştırma grubu oluşturulmuştur. Gruplar farklı hacim ve ergin arı yoğunluğuna göre düzenlenmiştirler. Araştırma grupları; standart kovanda 9 çerçeve arılı, standart kovanda 5 çerçeve arılı, 5 çerçeveli ruşet kovanda 5 çerçeve arılı, 5 çerçeveli ruşet kovanda 3 çerçeve arılı ve son olarak strafor ana arı çiftleştirme kutusu $(20 \times 15 \times 11 \mathrm{~cm}))$ ile oluşturulmuşlardır. Araştırma kolonilerine 3 defa iğneleme yöntemi ile hijyenik test uygulaması yapılmıştır.

Hijyenik test uygulanacak tüm kolonilerden yeni kapanmış pupaların olduğu bir çerçeve hijyenik davranış testini yapmak amacı ile belirlenmiştir. Bu çerçevede azot uygulaması sırasında zarar görmemeleri için çerçeve üzerindeki arılar silkelenerek kovan içerisine düşmeleri sağlanmıştır. Yağmacılığa ve kuluçka alanının ısı kaybına engel olmak amacı ile kovan kapatılıp üzerine kovanın örtü bezi konularak üzerindeki arıları uzaklaştırılan çerçeve test yapılacak alan üste gelecek şekilde yatay bir şekilde örtü bezinin üzerine yerleştirilmiştir.

Daha önceden özel bir ticari firmadan alınan $-196^{\circ} \mathrm{C}$ sıvı azot bir tank içerisinde kolonilere yakın yerlere taşınarak hazır tutulmuştur. Ayrıca, azot uygulaması yapılacak alanı belirlemek amaciyla üzerindeki ergin arılardan arındırılan yaklaşık 3 inç $(7,62 \mathrm{~cm})$ çapında daha önceden yaptırılan ve açık ucu inceltilerek keskinleştirilen metal silindir tüpler kullanılmıştır.

Hijyenik davranış testi yapılmak üzere belirlenen kapalı pupa alanına sahip çerçevenin petek gözleri üzerine metal silindirin keskin tarafı dikkatli bir şekilde yerleştirildikten sonra dikkatli ve yavaş bir basınç 
uygulayarak metal silindir tüpün yaklaşık 160 işçi pupasının bulunduğu daire alanın çevresine yaklaşık 0,5 $\mathrm{cm}$ gömülmesi sağlanmıştır. Daha sonra sıvı azot tankından alınan 250-300 ml miktarda sivı azot bir tarafi kapalı uzun kulplu silindir şeklindeki bir kepçe ile alınarak kapalı yavru alanı üzerine yerleştirilen silindir tüp içerisine dikkatli bir şekilde etrafa taşırmadan ve sıçratmadan dökülerek buharlaşması beklenmiştir.

Azot uygulaması yapılan çerçeveler alındığı kovan açılarak tekrar alındığı yere aynı konumda yerleştirilmiştir. $\mathrm{Bu}$ şekilde arılıklarda hijyenik davranış testleri yapılan koloniler yapılan test işleminden 24 saat sonra tekrar kontrol edilmiş geçen 24 saatlik süre içerisinde işçi arılar tarafından temizlenmiş boş petek gözü sayılarak kaydedilmiştir.

Hijyenik davranış testi yapılan kolonilerin toplam hijyenik davranış düzeyleri veya Temizleme Oranı (\%) aşağıdaki formülden yararlanarak belirlenmiştir (Palacia ve ark., 2005; Oskay ve ark., 2013).

$$
\text { Temizleme Oranı }(\mathrm{THB})(\%)=(\mathrm{a}-\mathrm{b}) / \mathrm{a} \times 100
$$

a: Azot uygulaması öncesi uygulama alanındaki kapalı pupa sayısı (160-boş göz sayısı)

b: Azot uygulamasindan 24 saat sonra temizlenmeyen kapalı pupa sayısı

İğneleme yönteminde yeni kapanmış yavrulu alanda 3 tane 7 adet kapalı yavru gözü olmak üzere toplam 21 adet kapalı yavru gözü üzerinden içerisine ince sivri uçlu bir toplu iğne ile gözün ortasından delinerek kıvrılmak sureti ile içerideki pupanın ölmesi sağlanmıştır (Spivak, 1996; Spivak ve Reuter, 2008). Bu gözlerin yerini belirlemek için her bir yedi gözün üzerine gelen kapalı göze bir işaret yapılmış ve 24 saat sonra bu işaret yardımı ile öldürülen pupaların temizlenme durumları kontrol edilmiştir.

Deneme süresince yukarda anlatılan yöntemle 3 farklı dönemde hijyenik davranış testi yapılarak mevsimin de hijyenik davranış üzerine etkisi belirlenmeye çalışılmıştır. Deneme süresince tüm koloniler eşit şartlar altında tutulmuşlardır.

Elde edilen oransal (\%) etkinlik değerleri Levene varyans homojenlik testine tabi tutulmuşlardır. Oransal (\%) etkinlik değerleri transformasyona tabi tutulmadan varyans analiz yöntemi ile analiz edilmiş olup grup ortalamaları arasındaki farklılıklar Duncan çoklu karşılaştırma testi ile karşılaştırılmışlardır.

\section{Bulgular ve Tartışma}

Bal arısı kolonilerinde görülen değişik hastalık ve parazitlere karşı mücadelede kimyasal kullanımını azaltmak veya ortadan kaldırmak için arıların hijyenik davranış özelliklerini belirlemede kullanılan yöntemlerden siv1 azot ve iğneleme yöntemlerinin karşılaştırıldığ 1 bu çalışmada koloni popülasyon yoğunluğu, kovan büyüklükleri ve tipleri ile test yapılan sezonun temizleme davranışı üzerine etkileri karşılaştırılmıştır.

İlk yıl; hijyenik davranışları belirlenmek üzere 20 şerli iki gruptan oluşan 40 koloni kullanılmıştır. I. grup kolonilere sıvı azot, II, grup kolonilere ise iğneleme yöntemi (Pin-killing) kullanılmıştır. Her iki grubun minimum, maksimum ve ortalama temizleme oranları tablo 1 de verilmiştir.

Tablo 1 incelendiğinde gruplardaki kolonilerin temizlik davranışı diğer bir ifade ile temizleme oranları arasında büyük bir varyasyon olduğu görülmektedir. Minimum temizleme oran1 \%35 iken maksimum temizleme oranı \%96 olmuştur. Yapılan hijyenik test sonucunda Siv1 azot (I. Grup) grubunda ortalama temizleme oranı \%66,25 olarak hesaplanırken Toplu iğne uygulaması yapılan II. grupta temizleme oranı $\% 78,10$ olarak belirlenmiştir. Ölü pupaları temizleme oranı bakımından gruplar arasındaki fark istatistiki olarak önemli bulunmuştur. Temizleme davranışının belirlenmesinde dünyada daha çok sıvı azot yöntemi kullanılıyor olsa da bu çalışmada Toplu iğne yönteminin de başarıyla kullanılabileceği hatta bu yöntemle kolonilerin temizleme davranışının daha yüksek olduğu belirlenmiştir. Toplu iğne yönteminde temizleme oranının daha yüksek olmasında öldürülen pupaların gözlerinde iğne ile açılan delik olması ve bu nedenle temizlikçi arıların içeride ölmüş bulunan pupadan daha hızlı haberdar olmaları ve daha hızlı bir şekilde temizlemeye başlamış olabilecekleri düşünülmektedir. Sivı azot yöntemi ile belirlenen temizleme oranı Oskay ve ark.(2013) tarafindan ilk yıl için bildirilen (\%43), Bak ve ark. (2010) tarafindan bildirilen (\%10) temizleme oranından daha yüksek, Güler ve Toy (2013) tarafindan bildirilen (\%76) temizleme oranından daha düşük bulunurken, Öztürk (2014)'ün bildirdiği değerle (\%69) yaklaşı1k olarak bulunmuştur. Toplu iğne yöntemi uygulanan grupta belirlenen ortalama temizleme oranı (\%73) Güler ve Toy (2013)'un bildirdiği değerle uyumlu bulunurken Öztürk (2014)'ün bildirdiği değerden daha yüksek bulunmuştur.

Birinci yıl hijyenik davranış oranı daha yüksek olan yöntem ve hijyenik davranış oranları yüksek koloniler belirlendikten sonra ikinci yıl hijyenik davranış oranı en yüksek olan koloni damızlık olarak kullanılmış ve bu koloniden alınan larvalarla ana arı yetiştirilerek kız kardeş ana arılardan oluşturulan 5 araştırma grubunda her biri 8 koloniden oluşan toplam 40 kolonili deneme arılığ düzenlenmiştir. Gruplar farklı hacim ve ergin arı yoğunluğuna göre düzenlenmiştirler. Araştırma grupları; standart kovanda 9 çerçeve arılı (I. Grup), standart kovanda 5 çerçeve arılı (II. Grup), 5 çerçeveli ruşet kovanda 5 çerçeve arılı (III. Grup), 5 çerçeveli ruşet kovanda 3 çerçeve arılı (IV. Grup) ve son olarak strafor çiftleştirme kutusu (V. Grup) ile oluşturulmuşlardır. Araştırma kolonilerine 3 defa iğneleme yöntemi (pinkilling) ile hijyenik test uygulaması yapılarak kovan hacminin ve içerisindeki arı yoğunluğunun temizleme davranışı üzerine etkileri belirlenmeye çalışılmıştır.

Tablo 2'de özetlendiği üzere bu denemede ortalama temizleme oranı 10 çerçevelik kovanda 9 çerçeve arının bulunduğu I. Grupta \%70,54, 10 çerçevelik kovanda 5 çerçeve arının bulunduğu II. Grupta \% $\% 8,38,5$ çerçevelik kovanda 5 çerçeve arının bulunduğu III. Grupta \%70,63, 5 çerçevelik kovanda 3 çerçeve arının bulunduğu IV. Grupta \%54,96 ve Ana arı çiftleştirmede kullanılan küçük kovanlardan oluşan V. Grupta ise \%58,21 olarak belirlenmiştir. 
Tablo 1 Sıvı azot ve iğneleme gruplarında ortalama temizlik davranışları

\begin{tabular}{l|cccc}
\multicolumn{1}{c|}{ Gruplar } & $\mathrm{n}$ & $\bar{X} \pm S^{\bar{x}}$ & En Az & En Çok \\
\hline 1. Grup(S1vı Azot) & 20 & $66,25 \pm 14,98 \mathrm{~b}^{*}$ & 35 & 90 \\
2. Grup(İğneleme) & 20 & $78,10 \pm 12,10 \mathrm{a}$ & 45 & 96 \\
Genel & 40 & $72,14 \pm 13,54$ & 35 & 96 \\
\hline
\end{tabular}

Tablo 2 Deneme gruplarında mevsimlere göre ortalama \pm S.H. hijyenik davranış değerleri

\begin{tabular}{|c|c|c|c|c|c|}
\hline Deneme Grupları & $\mathrm{n}$ & $\begin{array}{c}\text { Mayıs } \\
\text { 1.Test } \bar{X} \pm S^{\bar{x}}\end{array}$ & $\begin{array}{c}\text { Temmuz } \\
\text { 2.Test } \bar{X} \pm S^{\bar{x}}\end{array}$ & $\begin{array}{c}\text { Eylül } \\
\text { 3.Test } \bar{X} \pm S^{\bar{x}}\end{array}$ & Genel \\
\hline I. Grup & 8 & $72,50 \pm 9,27$ & $69,88 \pm 10,29$ & $69,25 \pm 8,45$ & $70,54 \pm 9,34^{* a}$ \\
\hline II. Grup & 8 & $57,50 \pm 9,30$ & $57,50 \pm 8,01$ & $60,13 \pm 8,01$ & $58,38 \pm 8,44^{\mathrm{b}}$ \\
\hline III. Grup & 8 & $72,25 \pm 7,79$ & $69,75 \pm 7,61$ & $69,88 \pm 7,85$ & $70,63 \pm 7,75^{\mathrm{a}}$ \\
\hline IV.Grup & 8 & $57,00 \pm 6,54$ & $53,13 \pm 7,90$ & $54,75 \pm 6,16$ & $54,96 \pm 6,87^{\mathrm{b}}$ \\
\hline V. Grup & 8 & $60,12 \pm 6,92$ & $57,24 \pm 6,90$ & $57,25 \pm 6,92$ & $58,21 \pm 6,91^{\mathrm{b}}$ \\
\hline Genel & 40 & $63,87 \pm 10,43$ & $61,50 \pm 10,51$ & $62,25 \pm 9,51$ & \\
\hline
\end{tabular}

*: Farklı harfler farklı istatistiksel grupları temsil etmektedir $(\mathrm{P}<0,01)$

Hijyenik davranış bakımından gruplar arasındaki farklılık istatistiki olarak önemli bulunmuştur $(\mathrm{P}<0,01)$ ve yapılan Duncan çoklu karşılaştırma testinde I. Grup ve III. Grup koloniler en iyi temizleme performansını göstererek aynı grupta yer alırken, II., IV. ve V. grup koloniler daha düşük bir temizleme performansı göstererek aynı grupta yer almışlardır. I. ve III. Gruptaki kolonilerin en iyi temizleme performansını göstermesi koloni populasyon yoğunluğunun (toplam işçi arı sayısı) temizlik davranışı üzerine önemli etkisinin olduğunu göstermektedir. Beş çerçeve arısı bulunan III. Grup kolonilerin yine beş çerçeve arısı bulunan II. Grup kolonilere göre daha iyi bir temizleme performansı göstermesi ise koloni populasyonu yanında kovan büyüklüğünün de temizlik performansında etkili olduğunu göstermektedir. Bir başka ifade ile koloni bireylerinin koloni içerisinde daha yoğun bir şekilde bulunması temizlik davranışını olumlu yönde etkilemektedir. V. Grupta çiftleştirme ruşetinde yoğun olarak bulunan az sayıdaki arının kendilerinden daha fazla olan IV. Gruptaki arılardan daha iyi bir temizleme performansı göstermesi de temizlik davranışı bakımından kovan içerisindeki arının yoğunluğunun da önemli olduğunu desteklemektedir.

Üç farklı sezonda yapılan hijyenik testlerde gruplar arasındaki farklılık çok büyük olmasa da Mayıs ayında yapılan testlerde koloniler daha iyi bir temizleme performansı göstermişlerdir. Bu durum mayıs ayında kolonilerde genç temizlikçi arı oranının daha yüksek olmasından kaynaklanabileceğini düşündürmektedir.

$\mathrm{Bu}$ çalışmada I.Grup ve III. Grupta belirlenen ortalama temizleme oranı $(\% 70,54$ ve $\% 70,63)$ Bak ve ark. (2010) tarafindan bildirilen $(\% 10)$ ve Oskay ve arkadaşları (2013) tarafindan bildirilen (\%43) değerlerinden yüksek, Öztürk (2014)'ün bildirdiği (\%69) değerle uyumlu iken Güler ve Toy (2013)'un bildirdiği (\%76) değerden biraz düşük bulunmuştur. Bu çalışmada bulunan temizleme oranının Güler ve Toy (2013)'un bildirdiği değerden düşük olmasında test yapılan bölgenin farklı olmasının ve bu çalışmada sayımların 24 saat sonra yapılmasına rağmen Güler ve Toy (2013)'un denemelerinde sayımların 48 saat yapılmış olmasının etkili olabileceği düşünülmektedir. $\mathrm{Bu}$ çalışmada gerek gruplar gerekse grup içerisindeki koloniler arasında varyasyonun yüksek çıkması bazı (Spivak ve Reuter, 1998;Wilkes ve Oldroyd 2002; Gülderen ve ark., 2007; Çakmak, 2010; Güler ve Toy, 2013;Öztürk, 2014) bildiriler ile uyumlu bulunmuştur

\section{Sonuc}

Arıcılarımızın bu tercihleri özelliklede kullandıkları ilaçların doz ayarlamasını iyi yapmadıklarında arıların hastalık ve zararlılarıyla mücadele ederken arılara ve arı ürünlerini tüketenlere de ciddi zararlar verebilmektedir. $\mathrm{Bu}$ çalışma arı hastalık ve zararlıları ile kimyasal mücadele yerine hastalık ve zararlılara daha dayanıklı hatların belirlenmesinde kullanılan hijyenik davranışın belirlenmesinde kullanılabilecek yöntemlerin etkinliklerinin belirlenmesine çalışılmıştır. Elde edilen sonuçlar, hijyenik davranışın belirlenmesinde mevsimin etkisinin çok önemli olmadığını ancak koloni gücünün ve özellikle de kovan büyüklüğüne göre arı yoğunluğunun önemli olduğunu en iyi sonucun kovan 10 çerçevelik ise 9 çerçeve arılı kolonilerden alındığını ancak 5 çerçevelik kovanlarda 5 çerçeve arı olan kolonilerde de benzer sonuçların alınabileceğini göstermiştir. Az sayıda arı popülasyonuna sahip küçük kovanlarda bile hijyenik testlerin başarıyla yapılabileceği görülmüştür. Arılarda yaygın olarak görülen hastalık ve zararlıların kontrolünde kimyasal kullanma yerine hijyenik davranış oranı yüksek olan kolonilerin belirlenerek damızlık olarak kullanılması ile zamanla kimyasal kullanımına gerek kalmayacağı veya çok sınırlı düzeyde kimyasal kullanımı ile hastalık ve zararlıların kontrol altında tutulabileceği tavsiye edilebilir. Bundan sonra daha kapsamlı, hijyenik davranış geliştirme ve hijyen kolonilerin hastalık ve zararlılara dayanıklılığını test eden ıslah programlarını da kapsayan çalışmaların yapılarak yüksek hijyenik fenotipik değerlere sahip arı popülasyonlarının oluşturulması önem arz etmektedir.

\section{Teşekkür}

$\mathrm{Bu}$ çalışma FEB-2011/07 no'lu proje kapsamında Ömer Halisdemir Üniversitesi Bilimsel Araştırma Projeleri Koordinasyon Birimi tarafindan desteklenmiştir. 


\section{Kaynaklar}

Akyol E, Kaftanoğlu O. 2001. Colony Characteristics and the Performance of Caucasian (Apis mellifera caucasica) and Mugla (Apis mellifera anatoliaca) Bees and Their Reciprocal Crosses. Journal of Apicultural Research: 40(34) : 11-15.

Akyol E, Korkmaz A. 2006. Varroa Destructor'un Biyolojik Kontrol Yöntemleri. Uludağ Arıcılık Dergisi. 6(2): 62-67.

Akyol E, Yeninar H, Karatepe B, Karatepe M, Özkök D. 2007. Effects of Queen age on Varroa (Varroa destructor) infestation level in honeybee (Apis mellifera caucasica) colonies and Colony Performance. Italian Journal and Animal Sciences. 6: 143-149.

Anonim. 2014. FAO Production Year Book, 2014.

Bak B, Wilde J, Siuda M. 2010. Comparision of hygienic behavior honey bees breeding lines. Journal of Apicultural Science. 54(2): 210-215

Çakmak İ. 2010. The over wintering survival of highly Varroa destructor infested honey bee colonies determined to be hygienic using the liquid nitrogen freeze killed brood assay. Journal of Apicultural Research and Bee World 49(2): 197201.

Genç F, Dülger C, Kutluca S, Dodoloğlu A. 1999. Kafkas Orta Anadolu ve Erzurum balarıs1 (Apis mellifera L.) genotiplerininin Erzurum koşullarındaki bazı davranış özelliklerinin karşılaştırılması. Tr. J. Of Veterinary and Animal Sciences. 23: 651-656s.

Ginevan ME, Lane DD, Greenberg L. 1982. Ambient air concentration of sulfur dioxide affects flight activity in bees. Apicultural Abst., 33(4): 244. Entomology Dept.

Gülderen Z, Tunca RI, Giray T, Kence M, Kence A. 2007. Türkiye Bal Arılarında (Apis mellifera L.) Hijyen Davranışı.

Güler A, Toy H. 2013. Relationship between dead pupa removal and season and productivity of honey bee(Apis mellifera, L.) colonies., Turkish Journal of Veterinary and Animal Sciences 37: 462-467.

Laidlaw HH, Page RE. 1997. Queen Rearing and Bee Breeding. Wicwas Press. Cheshire, connecticticut, USA. 224p.
Milani N. 1995. Morphometri of strains of Varroa jacobsoni Q. Resistant and susceptible to pyrethroids. Apimondia XXXIV International Apicultural Congress, 15-19 August, Lousanne, Sweden, Pp: 192.

Milani N, Vedova GD, Greatti M. 1995. A bioassay to test the susceptibility of Varroa jacobsoni to pyrethroids. Apimondia XXXIV International Apicultural Congress, 1519 August, Lousanne, Sweden, Pp: 192.

Oskay D, Kence A, Kence M, Doğaroğlu M, Giray T, Tunca RI, Erginoğlu S, Köseoğlu M. 2013. Improving resistance of American foulbrood in Mugla Honeybee (Apis mellifera anatolica) in Turkey Poster in Apimondia at Ukrainia.

Öztürk C. 2014. Doğu Akdeniz Bölgesi koşullarında yetiştiriciliği yapılan balarısı (Apis mellifera L.) kolonilerinde hijyenik davranış seleksiyonu ile hastalık ve parazitlere karşı dayanıklı hat geliştirme olanaklarının araştırılması, Ç.Ü. Fen Bilimleri Enstitüsü, Zootekni anabilim dalı, Doktora Tezi, Adana.

Palacia MA, Flores JM, Figini E, Ruffinengo S, Escande A, Bedascarrasbure E, Rodriguez E, Gonçalves LS. 2005. Evaluation of the time of uncapping and removing dead brood from cells by hygienic. Genet. Mol. Res. 4(1): 105114.

Rothenbuhler WC. 1964. Behaviour genetics of nest cleaning in honey bees. IV. Responses of F1 and backcross generations to disease-killed brood. American Zoologist, 4: 111-123.

Spivak M. 1996. Honey bee hygienic behavior and defence against Varroa jacobsoni. Apidologie 27: 245-260.

Spivak M, Reuter GS. 1998. Honey bee hygienic behavior. Am. Bee J. 138: 283-286.

Spivak M, Reuter GS. 2008. New Direction for the Minnesota Hygienic Line of Bees.

Tutkun E, İnci A, 1992. Bal arısı Zararlıları, Hastalıkları ve Tedavi Yöntemleri (Teşhisten Tedaviye). Demircioğlu Matbaacilik. 1-154.

Wilkes K, Oldroyd B. 2002. Breeding hygienic disease resistant bees. School of Biological Sciences University of Sydney RIRDC. 